\title{
Thrombin-activatable fibrinolysis inhibitor (TAFI) deficiency is compatible with murine life
}

\author{
Mariko Nagashima, ${ }^{1}$ Zheng-Feng Yin, ${ }^{2}$ Lei Zhao, ${ }^{1}$ Kathy White, ${ }^{3}$ Yanhong Zhu, ${ }^{4}$ \\ Nina Lasky, ${ }^{2}$ Meredith Halks-Miller, ${ }^{3}$ George J. Broze, Jr., ${ }^{2}$ William P. Fay, ${ }^{4}$ \\ and John Morser ${ }^{1}$ \\ ${ }^{1}$ Department of Cardiovascular Research, Berlex Biosciences, Richmond, California, USA
2Division of Hematology, Washington University School of Medicine, Barnes-Jewish Hospital, St. Louis, Missouri, USA
${ }^{3}$ Department of Pharmacology, Berlex Biosciences, Richmond, California, USA
${ }^{4}$ University of Michigan Medical Center, Ann Arbor, Michigan, USA
}

Address correspondence to: M. Nagashima, Department of Cardiovascular Research, Berlex Biosciences, 15049 San Pablo Avenue, Richmond, California 94804, USA.

Phone: (510) 669-4136; Fax: (510) 669-4246; E-mail: Mariko_Nagashima@berlex.com.

Received for publication January 5, 2001, and accepted in revised form November 13, 2001.

\begin{abstract}
To investigate the consequence of deficiency in thrombin-activatable fibrinolysis inhibitor (TAFI), we generated homozygous TAFI-deficient mice by targeted gene disruption. Intercrossing of heterozygous TAFI mice produced offspring in the expected Mendelian ratio, indicating that transmission of the mutant TAFI allele did not lead to embryonic lethality. TAFI-deficient mice developed normally, reached adulthood, and were fertile. No gross physical abnormalities were observed up to 24 months of age. Hematological analysis of TAFI-deficient mice did not show any major differences including plasma fibrinogen level, prothrombin time, and activated partial thromboplastin time. TAFI-deficient mice did not suffer from excess bleeding as determined by blood loss following tail transection, although their plasma failed to prolong clot lysis time in vitro. In vivo, TAFI deficiency did not influence occlusion time in either an arterial or a venous injury model. TAFI deficiency did not improve survival rate compared with the wild-type in thrombin-induced thromboembolism, factor $\mathrm{X}$ coagulant protein-induced thrombosis, and endotoxin-induced disseminated intravascular coagulation. Furthermore, TAFI deficiency did not alter kaolin-induced writhing response, implying that TAFI does not play a major role in bradykinin catabolism. The current study demonstrates that TAFI deficiency does not change normal responses to acute challenges.
\end{abstract}

J. Clin. Invest. 109:101-110 (2002). DOI:10.1172/JCI200212119.

\section{Introduction}

The fibrinolytic system is essential in the maintenance of blood vessel patency and removal of extravascular fibrin deposition. It is also thought to play a critical role in the degradation of extracellular matrices in concert with other proteinases in a number of physiological and pathological conditions (1-5). Plasmin is the key protease in the fibrinolytic system that degrades fibrin. It is converted from a circulating zymogen, plasminogen, by either tissue-type plasminogen activator ( $t-P A)$ or urokinase-type plasminogen activator (u-PA). Inhibition of the fibrinolytic system may occur at the level of plasmin by $\alpha 2$-antiplasmin or at the level of its activators by plasminogen activator inhibitors, predominantly PAI-1. Recently, another protein, thrombin-activatable fibrinolysis inhibitor, has been shown to inhibit the fibrinolytic system.

Thrombin-activatable fibrinolysis inhibitor (TAFI; EC 3.4.17.20) is a 60-kDa plasma glycoprotein that possesses carboxypeptidase B activity upon activation. This glycoprotein was originally described as a novel basic carboxypeptidase generated in serum following coagulation, which was distinct from carboxypeptidase $\mathrm{N}$
(EC 3.4.17.3), the key plasma enzyme responsible for degradation of anaphylatoxins $(6,7)$. Because of its instability, Hendriks et al. named it carboxypeptidase U (U referring to unstable; ref. 6), while Campbell et al. named it arginine carboxypeptidase (carboxypeptidase R; ref. 7). Meanwhile, a novel protein with a high affinity for plasminogen was isolated, cloned, and shown to have high-sequence homology to that of pancreatic procarboxypeptidase B (8). Following incubation with a serine protease such as trypsin or thrombin, this protein had carboxypeptidase B activity and was termed plasma procarboxypeptidase B. Subsequent characterization revealed the identity between carboxypeptidase $\mathrm{U}$ and plasma procarboxypeptidase B (9). The same protein was purified and characterized by Bazjar et al., who demonstrated that this protein inhibited fibrinolysis following its activation by thrombin, hence the name "thrombin-activatable fibrinolysis inhibitor" (10, 11). The potential role of this enzyme in the regulation of fibrinolysis was also suggested based on other in vitro and in vivo studies $(9,12-16)$.

In vitro TAFI is activated via proteolytic cleavage of a 92 amino acid-long activation peptide by a high con- 
centration of trypsin, thrombin, or plasmin to a zinc metalloprotease $(8-12)$. The activation of TAFI by thrombin is greatly enhanced in the presence of thrombomodulin $(11,14,16)$. In vitro activated TAFI (TAFIa) can cleave C-terminal basic residues from various natural and synthetic peptides, including biologically active peptides such as bradykinin and anaphylatoxins $(12,17,18)$. However, partially degraded fibrin is likely to be a physiological substrate of TAFIa. The newly exposed C-terminal lysine residues of fibrin following partial degradation by plasmin bind both plasminogen and t-PA with high affinity, thereby potentiating plasmin generation at the surface of fibrin clot (19-22). Activation of TAFI during clot lysis results in removal of these $\mathrm{C}$-terminal lysines, and consequently, reduced plasmin production, leading to a several-fold prolongation of clot lysis time. Numerous in vivo studies in the rabbit have demonstrated that inhibition of TAFI activity with carboxypeptidase inhibitor from potato (CPI) enhanced t-PA-induced thrombolysis as well as endogenous fibrinolysis (23-26). Furthermore, fibrin deposition in either the lung or kidney of the rat in response to endotoxin was reduced by inhibition of TAFI activity $(27,28)$. Therefore, accumulating evidence indicates that TAFI plays a role in the regulation of fibrinolysis in vivo with a caveat that in these studies CPI was used to preferentially block TAFI activity. While it is inactive against carboxypeptidase $\mathrm{N}$, it inhibits a number of other carboxypeptidases present in the body (for review, see ref. 29).

Mouse models deficient in each component of the fibrinolytic system have been generated to examine their role in development, thrombosis, thrombolysis, reproduction, wound repair, and cell migration (30-34). Unlike deficiency in coagulation factors such as tissue factor or factor $V$, which are embryonic lethal, deficiency in a component of the fibrinolytic system results in animals that develop normally with no obvious phenotypic abnormalities. However, plasminogendeficient mice suffered spontaneous thrombosis, and wound healing was grossly impaired $(32,33)$. Furthermore, plasminogen activator-deficient mice had impaired lysis of microthrombi in the lung and increased fibrin deposition in response to endotoxin challenge (31), while mice deficient in either PAI-1 or $\alpha 2$-antiplasmin had increased thrombolysis and were more resistant to endotoxin-induced thrombosis (30, 34). To examine the consequence of TAFI deficiency on endogenous fibrinolysis, as well as other prothrombotic challenges, we generated homozygous TAFI-deficient mice by targeted gene disruption. Such an animal model can also be used to determine if TAFI is involved in the turnover of biologically active peptides possessing C-terminal basic residues. Here we report the generation and characterization of TAFI-deficient mice.

\section{Methods}

Animals. All mice were maintained in an animal facility accredited by the Association for Assessment and
Accreditation of Laboratory Animal Care International. The protocols for in vivo studies were approved by Berlex Biosciences Animal Care and Use Committee. Mice were in a mixed background of C57BL/6 and 129/Sv and used at an age between 8 and 12 weeks old. For most of the studies, wild-type littermates were used as controls. However, for tail bleeding, thrombin-induced pulmonary thromboembolism, and LPS-induced disseminated intravascular coagulation studies in which large numbers of mice were required, offspring of TAFI-deficient mice used for breeding were compared with offspring of their wild-type littermates used for breeding. Materials. Human thrombin $(3,000 \mathrm{NIH} \mathrm{U/mg,}$ obtained by a direct comparison to an NIH thrombin reference standard; $1 \mathrm{NIH}$ unit equals $1.15 \mathrm{IU}$ ) was purchased from American Diagnostica Inc. (Greenwich, Connecticut, USA). Recombinant tissue-type plasminogen activator $(580,000 \mathrm{IU} / \mathrm{mg})$ was purchased from Genentech Inc. (South San Francisco, California, USA). Human thrombomodulin was purified as described previously (35). Endotoxin (Escherichia coli LPS, serotype 0111:B4), HEPES, and 3-[(3-cholamidopropyl)dimethylammonio]-1-propane-sulfonate (CHAPS) were obtained from Sigma Chemical Co. (St. Louis, Missouri, USA). Furylacryloyl-alanyl-arginine (FA-Ala-Arg) was from Bachem AG (Bubendorf, Switzerland). D-Phe-Pro-Arg chloromethylketone (PPACK) and D-Val-Phe-Lys chloromethylketone were obtained from Calbiochem-Novabiochem Corp. (San Diego, California, USA). Lovenox (enoxaparin sodium) was purchased from Aventis Pharmaceuticals Inc. (Bridgewater, New Jersey, USA).

Generation of TAFI gene-disrupted mice. The full-length murine TAFI cDNA was isolated from a mouse liver cDNA library (lambda ZAP; Stratagene, La Jolla, California, USA) using a partial human TAFI cDNA as probe. The murine TAFI cDNA was used to screen a P1 genomic library prepared from the genomic DNA isolated from the 129/Sv mouse (Genome Systems Inc., St. Louis, Missouri, USA). A 9.2-kb SacI fragment of TAFI DNA containing exons 6 to 9 and a 6.4-kb SpeI DNA fragment containing exon 10 were subcloned into pBluescript II KS (Stratagene) producing plasmids A and $\mathrm{B}$, respectively. For the construction of the targeting vector, a HSV-thymidine kinase (tk) cassette was placed at the KpnI site within the multiple cloning site of pBluescript II KS using blunt-end ligation. A 0.9-kb AccI-HindIII TAFI DNA fragment spanning a portion of intron 7 and half of exon 8 from plasmid A was subcloned into pET-21b (Stratagene) at its multiple cloning site. A XhoI-HindIII fragment containing the TAFI DNA was removed from the resulting PET- $21 \mathrm{~b}$ plasmid and was inserted between XhoI and HindIII sites directly after the tk cassette in the targeting vector. A SalI fragment containing a 1.5-kb PGK-neomycin phosphotransferase (neo) cassette was inserted into plasmid B directly upstream of the 6.4-kb TAFI DNA. Construction of the targeting vector was then completed by inserting a 7.9-kb XhoI-NotI DNA fragment from plas- 
mid B, containing the neo cassette and exon 10 of TAFI gene, between SalI and NotI sites of the targeting vector (Figure 1a). The targeting vector was linearized with NotI and introduced by electroporation into $129 / \mathrm{Sv}$ derived R1 embryonic stem cells (gift from A. Nagy, University of Toronto, Ontario, Canada), and stable transfectants were selected as described previously (36). Of 420 clones, two contained the expected allele as determined by Southern blot analysis. An embryonic stem cell clone was injected into C57BL/ 6 blastocysts as described (36), and the resulting male chimeras were bred to C57BL/ 6 females to generate heterozygous $F_{1}$ offspring. Heterozygous TAFI mice were intercrossed, yielding $\mathrm{TAFI}^{+/+}, \mathrm{TAFI}^{+/}$, and $\mathrm{TAFI}^{-/-} \mathrm{F}_{2}$ littermates.

Genotypic analysis. Genomic DNA was isolated from either tail clips or ear biopsies and used for genotyping by either Southern blot analysis or PCR analysis. For Southern blotting, a $0.45-\mathrm{kb}$ HindIII fragment of TAFI genomic DNA encompassing exon 6 was used as a hybridization probe. PCR analysis of the TAFI gene was performed using three primers derived from (a) the upstream portion of exon 8 (5'-AGAAAGGTGCGTCAAGTTCCTCC-3'), (b) a portion of exon 8 deleted in the mutant allele (5'GTTCTTCGTGGTCCTTGCTTTTG-3'), and (c) the neo cassette $\left(5^{\prime}\right.$-TTCCTGACTAGGgGagGagtagAag- $\left.3^{\prime}\right)$. The PCR product derived from the wild-type allele is $190 \mathrm{bp}$, and that derived from the mutant allele is $390 \mathrm{bp}$.

$R T$-PCR. mRNA was extracted from mouse liver using a FastTrack 2.0 kit (Invitrogen Corp., Carlsbad, California, USA) according to the manufacturer's instructions. First-strand cDNA was synthesized by oligo (dT) priming using the First-Strand cDNA Synthesis kit (Roche Molecular Biochemicals, Indianapolis, Indiana, USA). The first-strand cDNA product was used in the subsequent PCR amplification with primers, one annealing to the $5^{\prime}$ end of TAFI cDNA ( $5^{\prime}$-CAAGTCACTGTTGGGATGAAGC- $3^{\prime}$ ) and the second one annealing to the $3^{\prime}$ end of TAFI CDNA $\left(5^{\prime}\right.$-ATTAACTGTTCCTGATGACATGCC- $3^{\prime}$ ). All the PCR products were analyzed by electrophoresis on $1 \%$ agarose gels.

Determination of TAFI antigen in plasma. The presence of TAFI in plasma was demonstrated using either Western blot analysis or an ELISA. Mouse platelet-poor plasma was obtained by centrifugation of citrated blood (9:1 vol/vol with $3.8 \%$ sodium citrate) at $1,500 \mathrm{~g}$ for 15 minutes. For Western blot analysis, plasma was diluted fivefold with $0.1 \mathrm{M} \mathrm{NaCl}, 1 \mathrm{mM}$ EDTA, $0.05 \mathrm{M}$ Tris$\mathrm{HCl}, \mathrm{pH} 7.5$, and $10 \mu \mathrm{l}$ samples were separated by $10 \%$ SDS-PAGE. Western blot analysis was performed as described previously using rabbit Ab's raised against a peptide representing residues 155-167 (CGIHAREWISPAF) of mature TAFI $(36,37)$. The TAFI ELISA was performed using a commercial kit designed for detection of human TAFI (Enzyme Research Laboratories, South Bend, Indiana, USA), with purified human TAFI as a standard, according to the manufacturer's instructions without any modifications.

Determination of TAFIa and carboxypeptidase $N$ activity in plasma. To measure TAFIa activity, $75 \mu \mathrm{l}$ plasma was diluted with $25 \mu$ l of water and allowed to clot at room temperature with addition of thrombin $(4.5 \mathrm{NIH} \mathrm{U} / \mathrm{ml}$, final), thrombomodulin (50 $\mathrm{nM}$, final), and calcium chloride (17 mM, final). Ten minutes later, the clot was squeezed and discarded, and activation of TAFI was terminated by addition of PPACK $(1 \mu \mathrm{M}$, final). Total carboxypeptidase B activity (TAFIa and carboxypeptidase $\mathrm{N}$ activity) was measured by addition of a $40-\mu \mathrm{l}$ aliquot of the remaining fluid to $960 \mu \mathrm{l}$ of $0.02 \mathrm{M}$ Tris- $\mathrm{HCl}, \mathrm{pH}$ 7.8, $0.075 \mathrm{M} \mathrm{NaCl}$, and $0.1 \%$ (wt/vol) CHAPS containing FA-Ala-Arg ( $0.4 \mathrm{mM}$ final) as a substrate. The rate of hydrolysis of FA-Ala-Arg was determined by measuring changes in absorbance at $336 \mathrm{~nm}$ every 20 seconds for 10 minutes. Carboxypeptidase N (CPN) activity was measured similarly in the diluted plasma without addition of thrombin and thrombomodulin. The values for $\mathrm{CPN}$ thus obtained were same as those obtained by measuring the total carboxypeptidase B activity as described above, except in the presence of CPI.

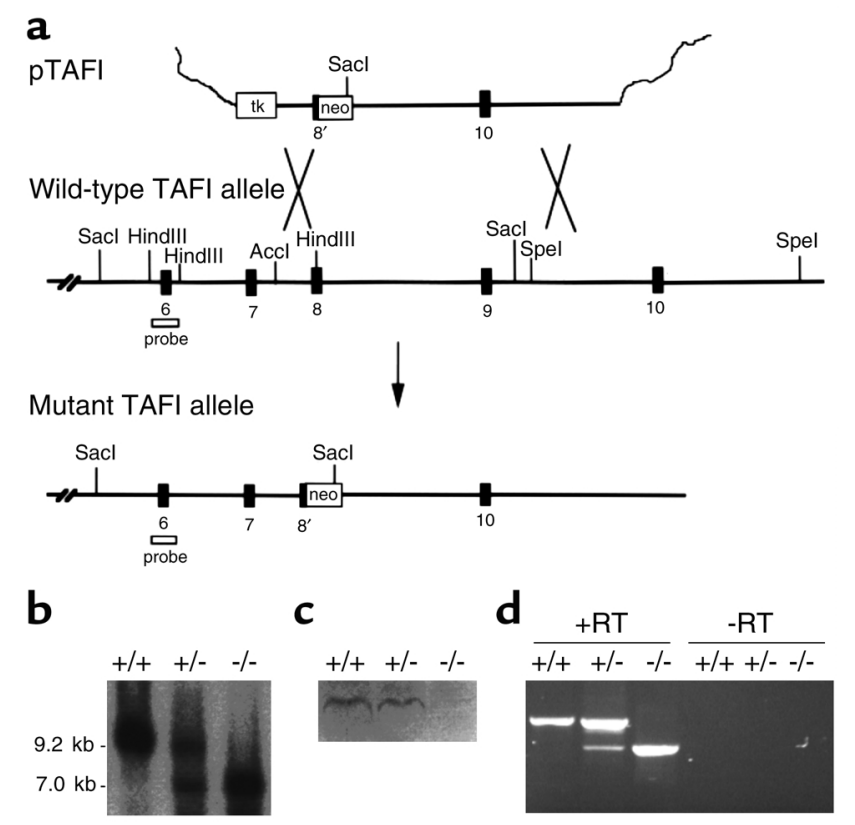

\section{Figure 1}

TAFI gene-disruption in mice. (a) TAFI replacement construct and partial restriction map of the endogenous locus. Exon 8 and 9 encodes some of the zinc and substrate binding sites of TAFI. (b) Southern blot analysis of TAFI gene disruption. The probe indicated in a was used to detect 9.2-kb DNA fragment in the wild-type allele and 7.0-kb DNA fragment in the mutant allele following Sac1 digestion of genomic DNA. (c) Western blot analysis of plasma TAFI from the wild-type, heterozygous, and homozygous TAFI mice. Ab raised against TAFI peptide (CGIHAREWISPAF) hybridized to a band with a molecular weight similar to that of murine albumin only in the plasma from the wild-type and heterozygous mice. (d) RT-PCR analysis of liver mRNA isolated from $\mathrm{TAFI}^{+/+}, \mathrm{TAFI}^{+/-}$, and $\mathrm{TAFI}^{-/-}$mice. $\mathrm{RT}-\mathrm{PCR}$ products obtained with primers that span the entire coding region ofTAFI cDNA in the presence of reverse transcriptase (RT) are shown on the left-hand side and those in the absence of reverse transcriptase are on the right-hand side. Neo, neomycin phosphotransferase gene; tk, thymidine kinase gene; probe, TAFI-specific probe used in Southern blot analysis (which encodes exon 6). 
Table 1

Plasma TAFI antigen and carboxypeptidases activities

\begin{tabular}{lccr}
\hline & $\mathrm{TAFI}^{+/+}$ & $\mathrm{TAFI}^{+/-}$ & \multicolumn{1}{c}{$\mathrm{TAFI}^{-/-}$} \\
TAFI antigen (nM, equivalent) & $0.62 \pm 0.23(n=5)$ & $0.34 \pm 0.12(n=6)$ & $0.07 \pm 0.03(n=7)$ \\
TAFla activity (mOD/min) & $0.88 \pm 0.33(n=5)$ & $0.52 \pm 0.29(n=6)$ & $0.1 \pm 0.15(n=7)$ \\
CPN activity (mOD/min) & $3.72 \pm 1.18(n=5)$ & $3.63 \pm 0.67(n=6)$ & $4.7 \pm 1.06(n=7)$ \\
\hline
\end{tabular}

TAFI antigen level in plasma was measured using an ELISA assay kit with purified human TAFI as a standard. TAFI activity in plasma was determined using FA-Ala-Arg as substrate following its activation with thrombin $(4.5 \mathrm{NIH} \mathrm{U} / \mathrm{ml})$, thrombomodulin $(50 \mathrm{nM})$, and $\mathrm{CaCl}_{2}(17 \mathrm{mM})$ as described in Methods. CPN activity was determined similarly without addition of thrombin, thrombomodulin, and $\mathrm{CaCl}_{2}$. The number of mice used in each group is indicated in parentheses. mOD, milli-optical density.

In vitro plasma clot lysis. The clot lysis profile of mouse plasma was determined using a 96-well microtiter plate clot lysis assay. Fifteen microliters of citrated plasma was mixed with $3 \mu \mathrm{l}$ of $2 \mu \mathrm{M}$ thrombomodulin and 60 $\mu \mathrm{l}$ of $0.04 \mathrm{M}$ HEPES, $\mathrm{pH} 7.0,0.15 \mathrm{M} \mathrm{NaCl}$, and $0.01 \%$ Tween 80 (vol/vol). The mixture was immediately added to another well containing $4 \mu \mathrm{l}$ of $75 \mathrm{NIH} \mathrm{U} / \mathrm{ml}$ thrombin, $2 \mu \mathrm{l}$ of $1 \mathrm{M} \mathrm{CaCl}_{2}$, and $4 \mu \mathrm{l}$ of $0.5 \mu \mathrm{g} / \mathrm{ml} \mathrm{t}-\mathrm{PA}$ in separate aliquots. The total volume of the mixture was made up to $120 \mu \mathrm{l}$ with water. After mixing, the change in absorbance at $405 \mathrm{~nm}$ was monitored at $37^{\circ} \mathrm{C}$ every minute for 60 minutes using a SpectraMAX 250 Microplate Spectrophotometer (Molecular Device Corp., Sunnyvale, California, USA). Lysis time was defined as the time at which the absorbance is one-half of the difference between the plateau reached after clotting and the base line value achieved at complete lysis. Hematological analysis, coagulation assays, and tail bleeding. Blood samples were collected from the inferior vena cava of animals into one-tenth volume of $3.8 \%$ sodium citrate. Blood cell counts were analyzed using a Baker 9120+CP Cell Counter (ABX Diagnostics Inc., Irvine, California, USA). Fibrinogen level was determined according to the method described by Macart (38), and the results are expressed as a percentage of the initial value. The activated partial thromboplastin time (aPTT) and prothrombin time (PT) were performed with platelet-poor plasma using an Electra $900 \mathrm{C}$ coagulometer (Beckman Coulter, Brea, California, USA). For blood chemistry analysis, serum was obtained from clotted whole blood and analyzed by IDEXX Veterinary Services Inc. (West Sacramento, California, USA). For measurement of tail bleeding, mice were anaesthetized with an intraperitoneal injection of pentobarbital (62.5 $\mathrm{mg} / \mathrm{kg}$ body weight), and a 1-mm segment was amputated from the tip using a device that cuts with a razor blade. The tail was immediately immersed in $25 \mathrm{ml}$ of saline prewarmed to $37^{\circ} \mathrm{C}$, with constant mixing. After 30 minutes, $5 \mathrm{ml}$ of $5 \%$ EDTA in PBS was added, and the number of red blood cells released from the tail wound into saline was determined with a Baker 9120+CP Cell Counter. For studying the effect of heparin on tail bleeding, mice were preinjected in the tail vein with Lovenox, a low-molecular-weight heparin $(3 \mathrm{mg} / \mathrm{kg}$ body weight) 2 minutes before tail amputation.

Mouse thrombosis models. A murine model of vascular injury induced by a photochemical reaction either in the artery or in the vein was performed as described previously (39). Briefly, either the left common carotid artery or the left jugular vein was isolated, and a vascular flow probe (Transonic Systems, Ithaca, New York, USA) was applied to monitor blood flow continuously. Rose bengal (Fisher Scientific Co., Pittsburgh, Pennsylvania, USA) at a concentration of $10 \mathrm{mg} / \mathrm{ml}$ in PBS was injected into the tail vein to administer a dose of $50 \mathrm{mg} / \mathrm{kg}$. A mid portion of either the common carotid artery or the jugular vein was illuminated with a 1.5-mW green light laser (540 nm; Melles Griot Inc., Irvine, California, USA) until an occlusive thrombus was formed. The time required to form the occlusive thrombus, defined as no detectable flow for 1.0 minute or more, was recorded. The operator was blinded to the genotype of mouse during the experiment.

In the thrombin-induced acute thromboembolism model, human thrombin was injected over 2 to $3 \mathrm{sec}-$ onds into the tail vein of conscious mice at a dose of $1,600,2,400$, or $3,200 \mathrm{NIH} \mathrm{U} / \mathrm{kg}$ body weight. The survival rate at 10 minutes after intravenous administration of thrombin was measured as an index of the severity of thromboembolism. In the endotoxin-induced septic shock model, mice were injected intraperitoneally with either $30 \mathrm{mg} / \mathrm{kg}$ or $40 \mathrm{mg} / \mathrm{kg}$ body weight of LPS dissolved in saline. The mice were observed for signs of endotoxemia daily, such as lethargy, scruffy fur, and some exudate from eyes, and survival time was recorded. In separate experiments, an effect of LPS on fibrin deposition in the kidney was investigated. Three hours after injection of LPS, mice were anesthetized and citrated blood was collected by cardiac puncture. Kidneys were perfused immediately with PBS containing 3.8\% sodium citrate, $100 \mu \mathrm{g} / \mathrm{ml}$ Lovenox, and $1 \mu \mathrm{M}$ D-Val-Phe-Lys chloromethylketone, followed by $4 \%$ paraformaldehyde (in PBS, sucrose $1 \% \mathrm{wt} / \mathrm{vol}$ ). The kidneys were harvested and fixed overnight with fresh $4 \%$ paraformaldehyde. Kidneys were cut in half and embedded in paraffin. Tissue sections ( $5 \mu \mathrm{M}$-thickness) were cut, hydrated, and incubated sequentially first with a solution of $3 \%$ hydrogen peroxide in PBS for 30 minutes and then a $10 \%$ normal goat serum in PBS at room temperature. Sections were immunostained for fibrin/fibrinogen using a rabbit antifibrinogen antiserum (kindly provided by J.L. Degen; University of Cincinnati, Ohio, USA; diluted $1: 1000, \mathrm{vol} / \mathrm{vol}$ ) followed by biotinylated goat anti-rabbit IgG, and detected with streptavidin peroxidase conjugate and diaminobenzidine (Zymed Laboratories, Inc., South San Francisco, California, USA). Following immunostaining, the extent of fibrin deposition was analyzed by a pathologist without prior knowledge of the genotype of the mice. In the factor $\mathrm{X}$ coagulant protein-induced (XCP-induced) subacute thrombosis model, mice were injected intraperitoneally with 
Table 2

$\mathrm{F}_{2}$ offspring of $\mathrm{TAFI}^{+/-}$matings

\begin{tabular}{lccc}
\hline Genotype $^{\mathrm{A}}$ & $\mathrm{TAFI}^{+/+}$ & $\mathrm{TAFI}^{+/-}$ & $\mathrm{TAFI}^{-/-}$ \\
Number of pups & 64 & 127 & 68 \\
Percentage of total & $25 \%$ & $49 \%$ & $26 \%$
\end{tabular}

${ }^{A}$ Genotype of offspring from intercrossing of heterozygous TAFI mice was determined by PCR.

$150 \mu \mathrm{g} / \mathrm{kg}$ body weight XCP from Russell viper venom. The survival rate, platelet counts, and fibrinogen level were determined at 2 and 16 hours.

Kaolin writhing test. Mice were injected intraperitoneally with $0.5 \mathrm{ml}$ kaolin suspended in saline $(5$ $\mathrm{mg} / \mathrm{ml}$ ) to introduce the writhing stretching response $(40,41)$. Subsequent writhing responses were counted over the next 15 minutes.

Statistical analysis. All data are presented as mean plus or minus SEM. The significance of differences in tail bleeding between groups was determined by ANOVA. For occlusion time, the nonparametric Kruskal-Wallis one-way ANOVA followed by the Mann-Whitney $U$ test was used. $P$ values less than 0.05 were considered significant.

\section{Results}

Generation of TAFI-deficient mice. To investigate in vivo consequences of TAFI deficiency, the TAFI gene was disrupted in mice as described in Methods. Successful gene targeting resulted in the replacement of a portion of exon 8 and 9 with a neo cassette (Figure 1a), thereby removing the DNA segment encoding residues critical for substrate and zinc binding essential for catalytic activity. The expected structure of the targeted TAFI locus was confirmed by Southern blot analysis. Thus, after SacI digestion of genomic DNA, the probe that encompasses exon 6 recognized a band of approximately $9.2 \mathrm{~kb}$ in the wild-type allele and a band of approximately $7.0 \mathrm{~kb}$ in the disrupted allele (Figure $1 \mathrm{~b})$. Germline transmission of the TAFI-null allele was achieved in a number of chimeric mice derived from two independent embryonic stem cell clones. Mice generated from both embryonic stem cell clones were characterized independently and were shown to be indistinguishable phenotypically. Consequently, most of the work described in the current study was performed with one line.

The targeted disruption of the TAFI gene resulted in the truncation of the TAFI transcript as shown by RT-PCR of mRNA isolated from the liver of homozygous TAFI-null mice (Figure 1d). The liver was the main tissue in which TAFI mRNA was detected by Northern blot analysis in the mouse $(42,43)$. Using primers that correspond to the $5^{\prime}$ and $3^{\prime}$ end of TAFI cDNA, the RT-PCR produced a fragment of approximately 1,000 bp in TAFI-deficient mice compared with a fragment of approximately $1,350 \mathrm{bp}$ in the wild-type littermates. The RT-PCR amplified both fragments when mRNA from heterozygous litter- mates was tested. In the absence of reverse transcriptase, no products were obtained.

To determine if the truncated TAFI transcript in the homozygous null mice leads to a synthesis of a truncated TAFI protein, Western blot analysis of plasma samples from different genotypes was performed. Polyclonal Ab's raised against a TAFI peptide corresponding to a region in the TAFI molecule that is encoded by exon 5 was used (Figure 1c). Therefore, if a truncated form of TAFI protein existed in circulation, it should be detected using this Ab. In the plasma from the wild-type and heterozygous TAFI mice, polyclonal Ab's bound to a band with a molecular weight slightly higher than that of albumin. This is consistent with the predicted molecular weight for mouse TAFI. On the other hand, no band was detected in the plasma from TAFI-deficient mice. The lack of TAFI protein in the plasma of TAFI-deficient mice was also demonstrated using a commercially available ELISA kit for detection of human TAFI, with purified human TAFI as standard. The plasma level of TAFI in heterozygous mice was found to be about half of that detected in the wild-type mice (Table 1). Only the background value in the ELISA was found with plasma samples from homozygous mice, which was similar to the value obtained with human plasma samples depleted of TAFI.

Viability and fertility of TAFI-deficient mice. DNA analysis of 259 progeny derived from $\mathrm{TAFI}^{+/-}$intercrosses showed that TAFI mice were born in the expected Mendelian ratio of one $\mathrm{TAFI}^{+/+} / \mathrm{two} \mathrm{TAFI}^{+/-} /$one $\mathrm{TAFI}^{-/}$ (Table 2). This indicated that TAFI deficiency did not lead to embryonic lethality. TAFI-deficient mice developed normally and reached adulthood. No physical abnormalities were observed in these mice up to 24 months of age. Matings of homozygous males with homozygous females produced viable offspring of normal litter size at normal frequency indicating that TAFIdeficient mice were fertile and pregnancies were carried to full term. Hematological analysis of $\mathrm{TAFI}^{-/-}$mice did not show any major differences in blood cell counts, plasma fibrinogen level, PT, and aPTT, compared with those of $\mathrm{TAFI}^{+/+}$mice (Table 3). There was no abnormality in liver and kidney functions as shown by blood chemistry analysis (Table 3 ).

\section{Table 3}

Hematological and hemostasis analysis

\begin{tabular}{lcc}
\hline & $\mathrm{TAFI}^{+/+}$ & $\mathrm{TAFI}^{-/-}$ \\
& $14.7 \pm 1.4(n=15)$ & $14.5 \pm 1.2(n=15)$ \\
Hemoglobin $(\mathrm{g} / \%)$ & $1013 \pm 176(n=15)$ & $1053 \pm 288(n=15)$ \\
Platelet count $\left(10^{9} / \mathrm{I}\right)$ & $100 \pm 35(n=15)$ & $96 \pm 26(n=15)$ \\
Fibrinogen $(\%)$ & $85.4 \pm 22(n=5)$ & $87.5 \pm 20(n=4)$ \\
Alkaline phosphatase $(\mathrm{IU} / \mathrm{I})$ & $25.8 \pm 4.7(n=5)$ & $24.3 \pm 5.8(n=4)$ \\
Blood urea nitrogen $(\mathrm{mg} / \mathrm{dl})$ & $0.44 \pm 0.06(n=5)$ & $0.5 \pm 0.08(n=4)$ \\
Creatine $(\mathrm{mg} / \mathrm{dl})$ & $10.9 \pm 0.41(n=6)$ & $11.3 \pm 0.38(n=6)$ \\
PT (s) & $19.3 \pm 0.97(n=6)$ & $20.0 \pm 0.83(n=6)$ \\
PTT(s) & & \\
\hline
\end{tabular}

For blood chemistry analysis, serum was obtained from clotted whole blood and analyzed by IDEXX Veterinary Services Inc. Fibrinogen level was measured according to the method described by Macart (38). The aPTT and PT were performed with platelet-poor plasma using a MLA Electra $900 \mathrm{C}$ coagulometer. The number of mice used in each group is indicated in parentheses. 

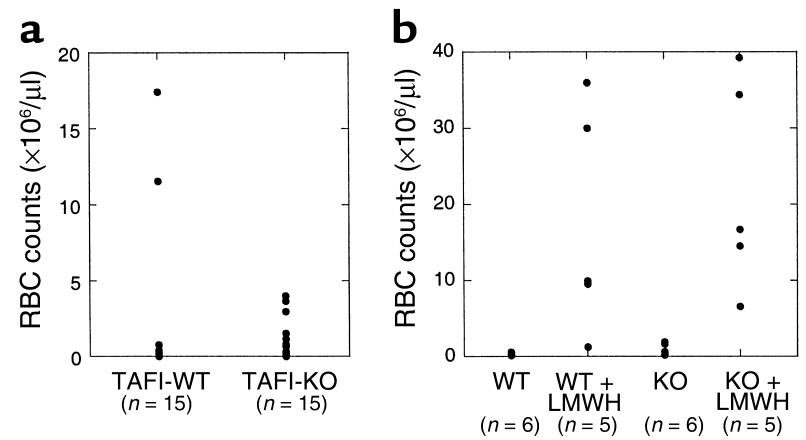

Figure 2

Tail bleeding. Wild-type mice and TAFI-deficient mice were anesthetized with an intraperitoneal injection of pentobarbital and a 1 -mm segment was amputated from the tip of the tail, as described in Methods. The tail was immediately immersed in saline at $37^{\circ} \mathrm{C}$. The amount of red blood cells released from the tail wound into saline was determined with a Baker $9120+$ CP Cell Counter (a). For tail bleeding in the presence of low-molecular-weight heparin, mice were injected with Lovenox ( $3 \mathrm{mg} / \mathrm{kg}$ body weight) in the tail vein 2 minutes before tail transection, and the amount of blood loss was measured similarly (b). The number of animals used in each group is indicated in parentheses. RBC, red blood cell; WT, wild-type; KO, knockout.

TAFI-deficient mice did not suffer from any apparent untoward effects of tail transection when samples were taken for genotyping. To evaluate the effect of TAFI deficiency on hemostasis, blood loss was determined during the 30 minutes following tail transection of a 1-mm segment. The mice used in the study had intact tails prior to the amputation because routine genotyping was performed with ear biopsies instead of tail clips. There was no statistically significant difference in the amount of blood loss between TAFI-deficient mice and the control mice (Figure 2a). It has been shown that the $129 / \mathrm{Sv}$ mice have significantly longer bleeding times than the $\mathrm{C} 57 \mathrm{Bl} / 6$ mice do, indicating that genetic backgrounds influence hemostasis (44). In this study, we compared offspring of TAFI-deficient mice with offspring of their wildtype littermates, rather than comparing among the same littermates. However, the present results were similar to those obtained from our previous study in which tail-bleeding time in TAFI-deficient mice was compared with their littermate controls and no differences were found (44). The effect of TAFI deficiency on bleeding was also studied in the presence of an antithrombotic agent that promoted exaggerated bleeding. In the presence of low-molecularweight heparin, there were wide individual differences in

\section{Figure 3}

the extent of bleeding. However, the blood loss in TAFIdeficient mice was not significantly different from that in the wild-type mice, implying that TAFI deficiency did not compromise hemostasis severely (Figure $2 \mathrm{~b}$ ).

Effect of TAFI deficiency on plasma carboxypeptidase activity and in vitro clot lysis. To demonstrate a role of activated TAFI in fibrinolysis, the effect of TAFI deficiency was tested in a plasma clot lysis assay. Coagulation and fibrinolysis were initiated in mouse platelet-poor plasma with thrombin and t-PA, respectively. In the presence of $50 \mathrm{nM}$ thrombomodulin, clot lysis time was prolonged at least twofold in plasma from wildtype mice (Figure 3a). This thrombomodulin-dependent prolongation was likely due to the activation of TAFI by a thrombin-thrombomodulin complex since an inhibitor of CPI reversed it (data not shown). A similar extent of prolongation was observed in plasma from heterozygous mice, indicating that while their plasma TAFI antigen level is about half of that in wildtype, enough TAFI is activated to perturb fibrinolysis. There was no prolongation of clot lysis time in plasma from TAFI-deficient mice upon the addition of thrombomodulin (Figure 3b). On the other hand, an addition of purified human TAFI to the same plasma resulted in a similar prolongation of clot lysis time as seen with plasma from the wild-type and heterozygous mice (data not shown). Therefore, activated TAFI is responsible for the retardation of fibrinolysis in the wild-type and heterozygous mice. These results are in agreement with TAFIa activity measured directly in these plasma samples with a small molecule substrate, FA-Ala-Arg, following in vitro activation with a thrombin/thrombomodulin complex (Table 1). Furthermore, it was evident that the activity of the second basic carboxypeptidase in plasma, CPN, remained relatively constant in the three groups of mice and that it did not influence fibrinolysis.
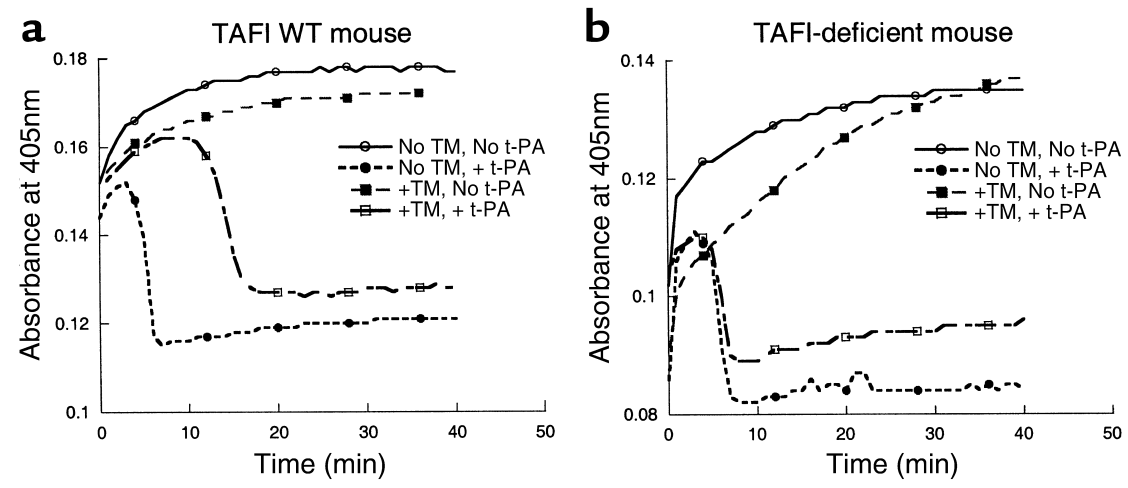

Plasma clot lysis profile. (a) represents wild-type mice and (b) represents TAFI-deficient mice. Clot formation and lysis were initiated in the recalcified $\left(\mathrm{Ca}^{2+}, 17 \mathrm{mM}\right)$ mouse plasma with human thrombin $(2.5 \mathrm{NIH} \mathrm{U} / \mathrm{ml})$ and t-PA $(0.017 \mu \mathrm{g} / \mathrm{ml})$, respectively. TM, human recombinant soluble thrombomodulin, was added at a final concentration of $50 \mathrm{nM}$ to enhance activation of endogenous TAFI. Absorbance at $405 \mathrm{~nm}$ was plotted against incubation time. Typical clot lysis profile obtained in the absence of TM and t-PA (solid line with open circle), in the absence of TM but presence of t-PA (dotted line with filled circle), in the presence of TM but absence of t-PA (dashed line with filled square), and in the presence of both TM and t-PA (dashed line with open square) is shown. 
Table 4

Survival rate in thrombin-induced acute pulmonary thromboembolism

\begin{tabular}{lcc}
\hline Thrombin dose & $\begin{array}{c}\text { Survival rate } \\
\text { in } \mathrm{TAFI}^{+/+}(\%)\end{array}$ & $\begin{array}{c}\text { Survival rate } \\
\text { in } \mathrm{TAFI}^{-/-}(\%)\end{array}$ \\
$1,600 \mathrm{NIH} \mathrm{U} / \mathrm{kg}$ & $87(n=8)$ & $62(n=8)$ \\
$2,400 \mathrm{NIH} \mathrm{U/kg}$ & $78(n=9)$ & $64(n=11)$ \\
$3,200 \mathrm{NIH} \mathrm{U} / \mathrm{kg}$ & $60(n=15)$ & $50(n=12)$
\end{tabular}

Human thrombin was injected intravenously over 2 to 3 seconds into the tai vein of conscious mice. The survival rate at 10 minutes after thrombin administration was taken as an index of the severity of pulmonary thromboembolism. The number of mice used in each group is indicated in parentheses.

Thrombosis models in TAFI-deficient mice. To investigate the effect of TAFI deficiency on the development of arterial thrombosis, TAFI-deficient mice and their wild-type littermates were subjected to a photochemical injury in the carotid artery and blood flow was monitored continuously. Mean time for an occlusive thrombus to form in TAFI-deficient mice was $59.2 \pm 5.2$ minutes $(n=15)$ compared with $59.1 \pm 6.3$ minutes in $\mathrm{TAFI}^{+/+}$mice $(n=14)$, indicating that TAFI deficiency did not influence the rate of acute thrombus formation significantly in this arterial thrombosis model. The effect of TAFI deficiency was also tested on venous thrombosis. Mean time for an occlusive thrombus formation was $55.8 \pm 43.8$ minutes $(n=4)$ in TAFI-deficient mice, and it was $81.8 \pm 41.4$ minutes $(n=6)$ in wild-type littermates. TAFI deficiency had no significant impact on the rate of venous thrombosis.

The potential involvement of TAFI in endogenous fibrinolysis was further examined in the thrombininduced acute thromboembolism, XCP-induced thrombosis, and endotoxin-induced disseminated intravascular coagulation models. In the acute thromboembolism model, intravenous injection of thrombin into conscious $\mathrm{TAFI}^{+/+}$mice resulted in death within 10 minutes in a dose-dependent manner (Table 4). There was no major difference in the survival rate between $\mathrm{TAFI}^{+/+}$and $\mathrm{TAFI}^{-/-}$mice. While a high dose of thrombin activates TAFI in vitro, it is not known if TAFI is activated following thrombin injection in vivo in this acute thrombosis model. Thus, TAFI-deficient mice were challenged with either endotoxin or XCP in chronic models. Sato et al. demonstrated previously that LPS injection caused activation of TAFI as well as induction of hepatic TAFI mRNA in mice (43). Following LPS injection (either $30 \mathrm{mg} / \mathrm{kg}$ or $40 \mathrm{mg} / \mathrm{kg}$ ), the survival rates were similar between TAFI-deficient and the wild-type mice (Figure 4). Because of reports on transient fibrin deposition in the kidney of mice injected with LPS $(34,45)$, in the separate experiments kidneys from animals injected with either a sublethal dose $(2 \mathrm{mg} / \mathrm{kg})$ or a lethal dose $(30 \mathrm{mg} / \mathrm{kg})$ of LPS 3 hours earlier were stained for fibrin. While there was some specific fibrin staining within the glomeruli of both the wild-type and TAFI-deficient littermates following LPS injection, there was no significant difference in the extent of staining between the two groups (data not shown). In XCP-challenged subacute coagulation model, the significant decreases in the plasma fibrinogen level and platelet counts observed at 2 hours and 16 hours after the stimulus were similar in both genotypes (Table 5). Furthermore, the survival rate did not differ between the two groups.

Kaolin-induced writhing test. Since it has been shown that TAFI cleaves C-terminal arginine residue from bradykinin in vitro $(12,17,18)$, the effect of TAFI deficiency on the writhing reaction induced by kaolin was studied in normal animals. The number of mice writhing during 15 minutes after the intraperitoneal injection of kaolin was $1.29 \pm 1.78(n=14)$ in the wildtype compared with $1.21 \pm 1.85(n=14)$ in TAFI-deficient mice. Kaolin is a known activator of factor XII and induces formation of bradykinin, which in turn induces writhing response. The result with TAFI-deficient mice demonstrated that TAFI does not play a major role in the degradation of bradykinin under normal conditions in this model.

\section{Discussion}

A correlation between fibrinolytic potential and the plasma level of TAFI antigen has been documented in the general population (46). In normal healthy subjects, plasma TAFI antigen level varies between $45 \%$ and $150 \%$ of the mean value (46-49). There are some reports that age influences the TAFI antigen level (47-49). The presence of polymorphisms in the TAFI gene has been observed (50-53), and it is now known that some of the polymorphisms are responsible for variations in the plasma TAFI antigen level $(52,53)$. The gene encoding human TAFI has been mapped to chromosome $13 q 14.11(54,55)$, but no known hemostatic disease is currently associated with this region; there has been no report of an individual lacking in plasma TAFI. One

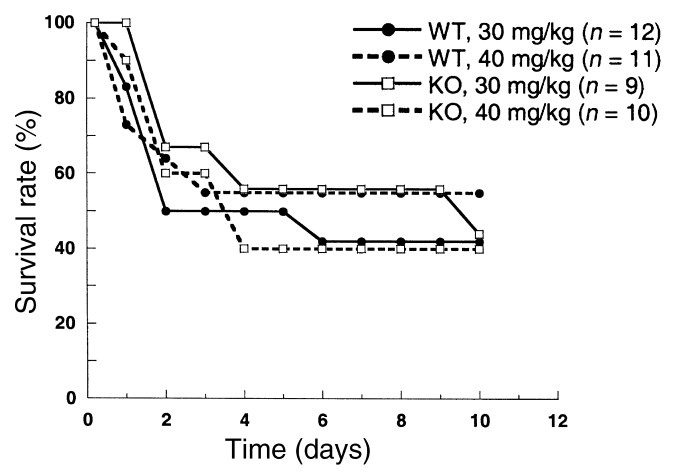

Figure 4

Effect of endotoxin on the survival of wild-type and TAFI-deficient mice. Mice were injected intraperitoneally with endotoxin (either 30 $\mathrm{mg} / \mathrm{kg}$ or $40 \mathrm{mg} / \mathrm{kg}$ body weight) dissolved in saline. The mice were observed daily for signs of endotoxemia, and survival time was recorded. Survival curve for wild-type mice injected with $30 \mathrm{mg} / \mathrm{kg}$ body weight (solid line with filled circle), with $40 \mathrm{mg} / \mathrm{kg}$ (dotted line with filled circle), TAFI-deficient mice injected with $30 \mathrm{mg} / \mathrm{kg}$ (solid line with open square), and with $40 \mathrm{mg} / \mathrm{kg}$ (dotted line with open square) is shown. The number of animals used in each group is indicated in parentheses. 
Table 5

Survival rate, fibrinogen level, and platelet counts following XCP challenge

\begin{tabular}{lcc}
\hline & $\mathrm{TAF}^{+/+}(n=15)$ & $\mathrm{TAFI}^{-/-}(n=15)$ \\
Survival rate (\%) & & \\
$\quad$ at 2 hours & 93 & 87 \\
$\quad$ at 16 hours & 53 & 60 \\
Plasma fibrinogen level (\%) & & \\
at 0 hours & $100 \pm 35$ & $56 \pm 26$ \\
at 2 hours & $52 \pm 23$ & $106 \pm 56$ \\
at 16 hours & $83 \pm 34$ & \\
Platelet counts $\left(10^{9} / \mathrm{I}\right)$ & & $1053 \pm 288$ \\
at 0 hours & $1013 \pm 176$ & $416 \pm 239$ \\
at 2 hours & $328 \pm 252$ & $353 \pm 142$ \\
at 16 hours & $319 \pm 285$ & \\
\hline
\end{tabular}

Mice were injected intraperitoneally with $150 \mu \mathrm{g} / \mathrm{kg}$ body weight factor $X$ coagulant protein from Russell viper venom. The survival rate, fibrinogen level, and platelet counts were determined 2 and 16 hours later. The number of mice used in each groups is indicated in parentheses.

study indicated an increased TAFI level was a mild risk factor for venous thrombosis (49). On the other hand, surprisingly, there has been a recent report that indicated lower levels of plasma TAFI as a risk factor for coronary heart diseases (56). Thus, we generated and characterized TAFI-deficient mice to study its pathophysiological role in various thrombotic diseases in the light of these current conflicting reports.

Mice deficient in TAFI were born without any abnormalities and developed normally to reach adulthood. They were fertile, producing viable offspring, which showed that TAFI deficiency was compatible with embryogenesis and development. Hematological and hemostatic analysis revealed no major differences between TAFI-deficient and wild-type mice, including tail bleeding. Previously, it was shown that in vitro clots formed from patient plasma deficient in coagulation factor VIII, IX, X, or XI lysed prematurely when induced by exogenous t-PA (36). When TAFI was activated upon addition of either the missing coagulation factor or thrombomodulin to such plasma, normal lysis was restored. Such data implicated a physiological role of TAFI in stabilization of newly formed fibrin clots. However, the results of tail bleeding in this study demonstrated that loss of TAFI did not lead to grossly impaired hemostasis.

The effect of TAFI deficiency was also studied in arterial as well as venous thrombosis models induced by a photochemical injury. In these models, initial formation of an occlusive thrombus depends on the balance between coagulation and fibrinolysis. TAFI deficiency did not have a significant impact on the rate of thrombus formation in either vessel. To test the possibility that enhanced endogenous fibrinolysis due to the absence of activated TAFI may facilitate spontaneous lysis of the stabilized clot, animals were allowed to recover, and the size of the residual thrombus was measured 24 hours later. We did not observe any statistically significant difference in the cross-sectional area of the thrombus from TAFI-deficient mice com- pared with that of the wild-type littermates (data not shown). Such results indicate that TAFI does not greatly influence the rate of spontaneous reperfusion. It is possible that PAI-1 release from the vessel wall in response to a photochemical injury may well mask any effect of TAFI. In the same arterial model, PAI-1 has been shown to affect both occlusion and spontaneous reperfusion rate $(57,58)$.

TAFI-deficient mice were challenged with other stimuli that are known to induce systemic intravascular coagulation. In a pulmonary thromboembolism model reported previously, intravenous injection of human thrombin into mice caused quick death (59-61). Fibrin deposition was detected in both large and small vessels in the lung $(59,61)$. In one of the papers, the authors demonstrated that thrombin-induced feedback activation of clotting factors, and subsequent additional formation of thrombin, and hence fibrin formation, contributed significantly to organ failures (61). Furthermore, it was proposed that thrombin-induced activation of factor XIII and/or TAFI, which render newly formed fibrin clots more resistant to plasmin degradation, as additional pathological mechanisms. In our study, survival rate determined at 10 minutes after thrombin injection was similar among TAFI-deficient mice compared with the wild-type. To investigate any subtle effect of TAFI deficiency in response to thrombin injection, tissue fibrin deposition was measured using ${ }^{125}$ I-labeled human fibrinogen in separate experiments. There was no significant accumulation of radioactivity in the lung and kidney of the control mice at any time point up to 6 hours after thrombin injection (our unpublished observations). Intravenous injection of thrombin does not lead to substantial accumulation of fibrin in the kidney or lung in mice.

Following endotoxin or XCP injection, there were no differences in the survival rate between the wild-type mice and TAFI-deficient mice. Yamamoto and Loskutoff showed that LPS-induced transient fibrin deposition in tissue-specific vasculature was likely due to activation of the coagulation cascade through induction of tissue factor expression, and concomitant suppression of the fibrinolytic system through increased PAI-1 and decreased urokinase-type tissue plasminogen activator (45). In numerous studies, agents that directly inhibit tissue factor or thrombin as well as agents that inhibit amplification of coagulation cascade such as activated protein $C$ have been effective in reducing endotoxin-induced lethality (for review, see refs. 62, 63). On the other hand, the effectiveness of an enhanced endogenous fibrinolytic system against a lethal dose of LPS has not been reported. However, reduced renal fibrin deposition in response to a nonlethal dose of endotoxin has been demonstrated in $\alpha_{2}$-antiplasmin-deficient mice $(34,64)$, but not in PAI1-deficient mice (64). In the current study, we did not detect any difference in the extent of fibrin deposition in the kidney of wild-type and their TAFI-deficient littermates in response to LPS. 
A potential involvement of TAFI in degradation of bradykinin was tested in TAFI-deficient mice using the kaolin-induced writhing model. Previous work has shown that kaolin induced writhing responses by way of bradykinin formation and that inhibition of the degradation of bradykinin by pretreatment of mice with a nonselective inhibitor of basic carboxypeptidases potentiated the writhing response in this model $(40,41)$. In the absence of circulating TAFI antigen, however, there was no potentiation of the writhing response, indicating that TAFI does not contribute significantly to the degradation of bradykinin under normal conditions.

In summary, we have generated and characterized TAFI-deficient mice. The current study demonstrated that TAFI deficiency is compatible with murine life. TAFI-deficient mice did not exhibit any abnormal phenotypes including hemostasis. Furthermore, the disruption of TAFI gene did not appear to participate in the acute challenges tested here. While it is evident from previous studies using TAFI inhibitors that TAFI plays a regulatory role in t-PA-induced thrombolysis (23-26), its effect on endogenous fibrinolysis may be more subtle. Our study also indicated that TAFI does not play a significant role in bradykinin turnover under normal conditions. Any potential role(s) of TAFI in the degradation of other biologically active peptides, especially anaphylatoxins, can now be tested unequivocally in TAFI-deficient mice instead of using nonselective inhibitors of basic carboxypeptidases. Currently, studies are underway to address these issues. During the preparation of our manuscript, Wagenaar et al. independently reported generation of TAFI-deficient mice and observed a lack of abnormal phenotypes in their TAFI-deficient mice, consistent with our result (65).

\section{Acknowledgments}

We thank Joseph Post for determination of aPTT and PT, Ron Vergona for helpful discussion, James Wang for statistical analyses, Bill Lillis and staff members of Animal Facilities at Berlex for animal care. We would also like to thank Bill Dole, Raju Mohan, Brad Buckman, and Katalin Kauser for their support.

1. Vasalli, J.-D., Sappino, A.-P., and Belin, D. 1991. The plasminogen activator/plasminogen system. J. Clin. Invest. 88:1067-1072.

2. Gurewich, V., Liu, J.-N., and Pannell, R. 1992. The intrinsic lysis concept. Ann. NY Acad. Sci. 667:224-232.

3. Collen, D., and Lijnen, H.R. 1994. Fibrinolysis and the control of hemostasis. In The molecular basis of blood diseases. 2nd edition. G. Stamatoyannopoulos, A.W. Nienhuis, P.W. Majerus, and H. Vamus, editors. W.B. Saunders Company. Philadelphia, Pennsylvania, USA. 725-752.

4. Verstraete, M. 1995. The fibrinolytic system: from Petri dishes to genetic engineering. Thromb. Haemost. 74:25-35.

5. Plow, E.F., Allampallam, K., and Redlitz, A. 1997. The plasma carboxypeptidases and the regulation of the plasminogen system. Trends Cardiovasc. Med. 7:71-75.

6. Hendriks, D., Scharpe, S., van Sande, M., and Lommaert, M.P. 1989. Characterization of a carboxypeptidase in human serum distinct from carboxypeptidase N. J. Clin. Chem. Clin. Biochem. 27:277-285.

7. Campbell, W., and Okada, H. 1989. An arginine specific carboxypeptidase generated in blood during coagulation or inflammation which is unrelated to carboxypeptidase $\mathrm{N}$ or its subunits. Biochem. Biophys. Res. Commun. 162:933-939.

8. Eaton, D.L., Malloy, B.E., Tsai, S.P., Henzel, W., and Drayna, D. 1991. Isolation, molecular cloning and partial characterization of a novel carboxypeptidase B from human plasma. J. Biol. Chem. 266:21833-21838.
9. Wang, W., Hendriks, D.F., and Scharpe, S.S. 1994. Carboxypeptidase U, a plasma carboxypeptidase with high affinity for plasminogen. J. Biol. Chem. 269:15937-15944.

10. Bajzar, L., Manuel, R., and Nesheim, M.E. 1995. Purification and characterization of TAFI, a thrombin-activatable fibrinolysis inhibitor. J. Biol. Chem. 270:14477-14484.

11. Bajzar, L., Morser, J., and Nesheim, M.E. 1996. TAFI, or plasma procarboxypeptidase B, couples the coagulation and fibrinolytic cascade through the thrombin-thrombomodulin complex. J. Biol. Chem. 271:16603-16608.

12. Tan, A.K., and Eaton, D.L. 1995. Activation and characterization of procarboxypeptidase B from human plasma. Biochemistry. 334:5611-5816.

13. Redlitz, A., Tan, A.K., Eaton, D.L., and Plow, E.F. 1995. Plasma carboxypeptidases as regulators of the plasminogen system. J. Clin. Invest. 96:2534-2538.

14. Sakharov, D.V., Plow, E.F., and Rijken, D.C. 1997. On the mechanism of the antifibrinolytic activity of plasma carboxypeptidase B. J. Biol. Chem. 272:14477-14482.

15. von dem Borne, P.A.K., Bajzar, L., Meijers, J.C.M., Nesheim, M.E., and Bouma, B.N. 1997. Thrombin-mediated activation of factor XI results in a TAFI-dependent inhibition of fibrinolysis. J. Clin. Invest. 99:2323-2327.

16. Hosaka, Y., Takahashi, Y., and Ishii, H. 1998. Thrombomodulin in human plasma contributes to inhibit fibrinolysis through acceleration of thrombin-dependent activation of plasma carboxypeptidase B. Thromb. Haemost. 79:371-377.

17. Shinohara, T., et al. 1994. Pro-carboxypeptidase R cleaves bradykinin following activation. Int. Arch. Allergy Immunol. 103:400-404.

18. Campbell, W., Okada, N., and Okada, H. 2001. Carboxypeptidase R is an inactivator of complement-derived inflammatory peptides and an inhibitor of fibrinolysis. Immunol. Rev. 180:162-167.

19. De Vries, C., Veerman, H., and Pannekoek, H. 1989. Identification of the domains of tissue-type plasminogen activator involved in the augmented binding of fibrin after limited digestion with plasmin. J. Biol. Chem. 264:12604-12610.

20. Higgins, D.L., and Vehar, G.A. 1987. Interaction of one-chain and twochain tissue plasminogen activator with intact and plasmin-degraded fibrin. Biochemistry. 26:7786-7791.

21. Thorsen, S. 1992. The mechanism of plasminogen activation and variability of the fibrin effector during tissue-type plasminogen activatormediated fibrinolysis. Ann. NY Acad. Sci. 667:52-63.

22. Stewart, R.J., Fredenburgh, J.C., Rischke, J.A., Bajzar, L., and Weitz, J.I. 2000. Thrombin-activatable fibrinolysis inhibitor attenuates (DD)Emediated stimulation of plasminogen activation by reducing the affinity of (DD)E for tissue plasminogen activator. J. Biol. Chem. 275:36612-36620.

23. Minnema, M.C., et al. 1998. Enhancement of rabbit jugular vein thrombolysis by neutralization of factor XI. J. Clin. Invest. 101:10-14.

24. Klement, P., Liao, P., and Bajzar, L. 1999. A novel approach to arterial thrombolysis. Blood. 94:2735-2743.

25. Nagashima, M., et al. 2000. An inhibitor of activated thrombin-activatable fibrinolysis inhibitor potentiates tissue-type plasminogen activatorinduced thrombolysis in a rabbit jugular vein thrombolysis model. Thromb. Res. 98:333-342.

26. Refino, C.J., et al. 2000. Consequences of inhibition of plasma carboxypeptidase $\mathrm{B}$ on in vivo thrombolysis, thrombosis and hemostasis. Fibrinolysis and Proteolysis. 14:305-314.

27. Nerme, V., Akerblom, B., Legnehed, A., Scharpe, S., and Hendriks, D. 2000. Carboxypeptidase $U$ inhibitors increase the rate of fibrinolysis in a rat DIC model. Fibrinolysis and Proteolysis. 14:69. (Abstr.)

28. Muto, Y., Suzuki, K., and Shii, H. 2000. TAFIa inhibitors enhance fibrinolysis in tissue factor-induced rat DIC model. Fibrinolysis and Proteolysis. 14:70. (Abstr.)

29. Skidgel, R.A. 1996. Structure and function of mammalian zinc carboxypeptidases. In Zinc metalloproteases in bealth and diseases. N.M. Hooper, editor. Tayler and Francis Ltd. London, United Kingdom. 241-283.

30. Carmeliet, P., et al. 1993. Plasminogen activator inhibitor-1 gene deficient mice. II. Effects on hemostasis, thrombosis and thrombolysis. J. Clin. Invest. 92:2756-2760.

31. Carmeliet, P., et al. 1994. Physiological consequences of loss of plasminogen activator gene function in mice. Nature. 368:419-424.

32. Bugge, T.H., Flick, M.J., Daugherty, C.C., and Degen, J.L. 1995. Plasminogen deficiency causes severe thrombosis but compatible with development and reproduction. Genes Dev. 9:794-807.

33. Romer, J., et al. 1996. Impaired wound healing in mice with a disrupted plasminogen gene. Nat. Med. 2:287-292.

34. Lijnen, H.R., Okada, K., Matsuo, O., Collen, D., and Dewerchin, M. 1999. $\alpha 2$-antiplasmin gene deficiency in mice is associated with enhanced fibrinolytic potential without overt bleeding. Blood. 93:2274-2281.

35. Glaser, C.B., et al. 1992. Oxidation of a specific methionine in thrombomodulin by activated neutrophil products blocks cofactor activity. J. Clin. Invest. 90:2565-2573.

36. Broze, G., and Higuchi, D.A. 1996. Coagulation-dependent inhibition of 
fibrinolysis: role of carboxypeptidase- $U$ and the premature lysis of clots from hemophilic plasma. Blood. 88:3815-3823.

37. Huang, Z-F., Higuchi, D., Lasky, N., and Broze, G.J., Jr. 1997. Tissue factor inhibitor (TFPI) gene-disruption produces embryonic lethality in mice. Blood. 90:944-951.

38. Macart, M., Koffi, A., Henocque, G., Mathieu, J-F., and Guilbaud, J-C. 1989. Optimized microturbidometric assay for fibrinogen. Clin. Chem. 35:211-214.

39. Eitzman, D.T., Westrick, R.J., Xu, Z., Tyson, J., and Ginsburg, D. 2000. Hyperlipidemia promotes thrombosis after injury to atherosclerosis vessels in apolipoprotein E-deficient mice. Arterioscler. Thromb. Vasc. Biol. 20:1831-1834

40. Fujiyoshi, T., et al. 1989. Kaolin-induced writhing in mice, a new model of possible bradykinin-induced pain for assessment of analgesic agents. Agents Actions. 27:332-334.

41. Chau, T.T., Lewin, A.C., Walter, T.L., Carlson R.P., and Weichman, B.M. 1991. Evidence for a role of bradykinin in experimental pain models. Agents and Actions. 34:235-238.

42. Marx, P.F., et al. 2000. Characterization of mouse thrombin-activatable fibrinolysis inhibitor. Thromb. Haemost. 83:297-303.

43. Sato, T., et al. 2000. Pro-carboxypeptidase $\mathrm{R}$ is an acute phase protein in the mouse, whereas carboxypeptidase $\mathrm{N}$ is not. J. Immunology. 165:1053-1058.

44. Broze, G.J., Jr., Yin, Z.-F., and Lasky, N. 2001. A tail vein bleeding time model and delayed bleeding in hemophiliac mice. Thromb. Haemost. 85:747-748.

45. Yamamoto, K., and Loskutoff, D.J. 1996. Fibrin deposition in tissues from endotoxin-treated mice correlates with decreases in the expression of urokinase-type but not tissue-type plasminogen activator. J. Clin. Invest. 97:2440-2451

46. Mosnier, L.O, von dem Borne, P.A.K., Meijers, J.C.M., and Bouma, B.N 1998. Plasma TAFI levels influence the clot lysis time in healthy individuals in the presence of an intact intrinsic pathway of coagulation. Thromb. Haemost. 80:829-835.

47. Schatteman, K.A., Goossens, F.J., Scharpe, S.S., Neels, H.M., and Hendriks, D.F. 1999. Assay of procarboxypeptidase U, a novel determination of the fibrinolytic cascade, in human. Clin. Chem. 45:807-813.

48. Chetaille, M.C.A., Kouassi, D., Morange, P.E., and Juhan-Vague, I. 2000. Plasma TAFI antigen variations in healthy subjects. Thromb. Haemost. 83:902-905.

49. van Tilburg, N.H., Rosendaal, F.R., and Bertina, R.M. 2000. Thrombin activatable fibrinolysis inhibitor and the risk for deep vein thrombosis. Blood. 95:2855-2859.

50. Zhao, L., Morser, J., Bajzar, L., Nesheim, M., and Nagashima, M. 1998. Identification and characterization of two thrombin-activatable fibrinolysis inhibitor isoforms. Thromb. Haemost. 80:949-955.

51. Boffa, M.B., Reid, S., Joo, E., Nesheim, M.E., and Koschinsky, M. L. 1999. Characterization of the gene encoding human TAFI (Thrombin-acti- vatable fibrinolysis inhibitor; plasma procarboxypeptidase B). Biochemistry. 38:6547-6558.

52. Crainich, P., et al. 2000. A polymorphism at position -438 in the promoter region of thrombin-activatable fibrinolysis inhibitor is strongly associated with plasma antigen level in healthy older men and women. Circulation. 102(Suppl. II):866. (Abstr.)

53. Henry, M., et al. 2001. Identification of polymorphisms in the promoter and the 3 ' region of the TAFI gene: evidence that plasma TAFI antigen levels are strongly genetically controlled. Blood. 97:2053-2058.

54. Tsai, S.P., and Drayna, D. 1992. The gene encoding human plasma carboxypeptidase B resides on chromosome 13. Genomics. 14:549-550.

55. Vanhoof, G., et al. 1996. The gene for human carboxypeptidase U maps to $13 q 14.11$. Genomics. 38:454-455.

56. Morange, P.E., et al. 2001. Evaluation of TAFI plasma antigen and genotypes in myocardial infarction patients and controls from the North and South Europe (HIFMECH Study). Suppl. Thrombo. Haemost. [Online resource.] 85:OC977. http://www.cartesian-secure.com/isth2001.

57. Eitzman, D.T., Westrick, R.J., Nable, E.G., and Ginsburg, D. 1999. Plasminogen activator- 1 and vitronectin promote vascular thrombosis in mice. Blood. 95:577-580.

58. Matsuno, H., et al. 1999. Differential role of components of the fibrinolytic system in the formation and removal of thrombus induced by endothelial injury. Thromb. Haemost. 81:601-604.

59. Gomi, K., et al. 1990. Antithrombotic effect of recombinant thrombomodulin on thrombin-induced thromboembolism in mice. Blood. 75:1396-1399.

60. Witt, W., Fredrich, M., Wydro, R., and Morser, J. 1993. Antithrombotic effects of recombinant soluble human thrombomodulin analogs in animal models of tissue-factor and thrombin induced DIC. In DIC: pathogenesis, diagnosis and therapy of disseminated intravascular fibrin formation. G. Muller-Berghaus, editor. Elsevier Science Publishers B.V. Amsterdam, The Netherlands. 233-238.

61. Gresele, P., et al. 1998. Activated human protein C prevents thrombininduced thromboembolism in mice. Evidence that activated protein $\mathrm{C}$ reduces intravascular fibrin accumulation through the inhibition of additional thrombin generation. J. Clin. Invest. 101:667-676.

62. Levi, M., de Jonge, E., van der Poll, T., and ten Cate, H. 1999. Disseminated intravascular coagulation. Thromb. Haemost. 82:695-705.

63. Esmon, C.T. 2000. Introduction: are natural anticoagulants candidates for modulating the inflammatory response of endotoxin? Blood. 95:1113-1116.

64. Dewerchin, M., Collen, D., and Lijnen, H.R. 2001. Enhanced fibrinolytic potential in mice with combined homozygous deficiency of $\alpha 2$ antiplasmin and PAI-1. Thromb. Haemost. 86:640-646.

65. Wagenaar, G.T.M, et al 2001. Generation and characterization of thrombin activatable fibrinolysis inhibitor deficient mice. Suppl. Thrombo. Haemost. [Online resource.] 85:OC1759. (Abstr.) http://www.cartesian-secure.com/isth2001. 